\title{
Discrimination of the saturated vapours of alcohols by the responses of assembly of piezoquartz sensors covered with metal stearates and their complexes with octadecylamine
}

\author{
A.P. Filippov, P.E. Strizhak, D.I. Denisyuk, T.G. Serebry, T.S. Ivaschenko \\ L.V. Pysarzhevsky Institute of Physical Chemistry, NAS of Ukraine \\ 31, prospect Nauky, 03028 Kyiv, Ukraine \\ E-mail:pstrizhak@hotmail.com
}

\begin{abstract}
The sensitivity of sensor assembly based on piezoquartz resonators (PQR) with the chemical coatings of the specified type relatively to the saturated vapours of several lowest alcohols is investigated. As the chemical coatings, some complex compounds of d-transition metals with stearate anion ( $\left.\mathrm{St}^{-}\right)$and octadecylamine (ODA) of the general formula $\mathrm{M}(\mathrm{ODA})_{\mathrm{N}} \mathrm{St}_{2}$ were used, where $\mathrm{M}^{2+}$ are ions of d-transition metals $\mathrm{Cu}(\mathrm{II}), \mathrm{Co}(\mathrm{II}), \mathrm{Ni}(\mathrm{II})$, and $\mathrm{N}$ was equal $0,2,4$, and 6 . The sensor images for each of all alcohols investigated by us has the unique character that can be used for discrimination between individual alcohols by using the set of coatings of PQR sensors applied in this work.
\end{abstract}

Keywords: piezoquartz sensor, alcohols, d-transition metal complex.

Manuscript received 01.03.06; accepted for publication 29.03.06.

\section{Introduction}

Expansion of assortment of alcoholic drinks in the consumer market especially last years is accompanied by the growth of release under the guise of known commodity marks of obvious fakes or production of obviously poor quality. The wide circulation was obtained with shadow business on manufacturing strong alcoholic drinks from the poor-quality and noncertificated raw material, cases of poisonings with drinks of this kind are frequent. Organoleptic parameters at assortment identification of drinks possess a low degree of reliability more often, and they usually become covering for falsification. Therefore, the need for development of objective express trains - techniques of quality assurance of specified production with the help of display chemical reactions as well as physical and chemical methods of the analysis grows continuously. Among the perspective principles of such control there can become the identification of a product smell using the multisensor devices, for example, assembly from several piezoquartz resonators (PQR) with sensitive chemical coatings, the so-called "electronic nose" (EN). For the development of such devices with a reference to the above mentioned problem, a necessary stage is research of sensitivity and selectivity of multisensor assembly in relation to different components of a controllable product. Among them, there can be both substances inherent to it (i.e., describing its assortment an accessory) and unusual (i.e., characteristic falsifications for means).

The most full and authentic analysis of quality and authenticity of various grades of vodka or cognacs could be provided by known methods of gas and liquid chromatography as well as other tool methods of the chemical analysis with use of computer systems and databases. However, such analysis demands the expensive equipment, presence of the highly skilled attendants and can be carried out only in stationary laboratories. It limits an opportunity of wide application of these means for mass quality assurance of specified production on manufacturing and in trade enterprises. For such purposes the most suitable can be the portable analyzer of smells such as EN in which the assembly of sensors based on PQR with the sensitive chemical coatings put on them is used. Development of such devices is impossible without creation of the sensitive chemical coatings possessing even partial selectivity in relation to various alcohols.

A number of attempts to create such devices are described in the literature with use of gas chromatographic stationary phases, polymers, propolis and other substances of the various nature as sensitive coatings [1-3].

So, in the work [3] by development of approaches to create EN for testing cognac and coffee aroma as chemical coatings for PQR sensors sensitive to alcohols, the following adsorbents have been recommended: PEG- 
2000, dinonylphtalate, methysilicon oil, Triton X-100, polyethylene glycole adipinate and polystyrene. Among them, the first three adsorbents represent viscous liquids that results in attenuation of a volume acoustic wave both with increase in thickness of the adsorbent film and with the weights of alcohol adsorbed by this film. It results in the fact that these sensors with such coatings give a nonlinear dependence of PQR frequency leaving $(\Delta f)$ on the analyte vapour concentration. Moreover, this dependence passes through the peak when achieving the certain degree of saturation of a sorbent film with analyte what demands special receptions for application of such sensors, for example, record "chrono-frequencygram" that is registration of changes $\Delta f$ with time [3].

In our opinion, assembly of the sensors, capable to distinguish organic substances of different chemical nature, and, especially, substances of the same class (alcohols) in presence of water vapours, it is expedient to create with use of the solid chemical coatings having, basically, the hydrophobic nature. Such coatings in the sensor assembly should differ among themselves not only in relation to various polarity of molecules of different alcohols, but also in relation to a structure of the hydrocarbonic radical in the molecule of the given alcohol.

Discrimination ability of a sorbent concerning a structure of a hydrocarbonic radical can be appreciably caused by the shape of hydrophobic cavities in the structure of the sorbent film in which the given hydrocarbonic radical can be inserted more or less complementarily in relation to points of the cavity, capable to carry out weak cooperative interactions with the adsorbate molecule.

It is known that the structure of hydrophobic micropores can be generated by long chain hydrocarbonic tails of surface-active substances (SAS) organized in Lengmuir-Blodgett (LB) films on a surface of any solid substrate [4], or included into a matrix of mesoporous silica [5]. Pure SAS themselves at usual temperature are liquid substances or have low temperature of fusion. SAS molecules fixed on a surface of a solid substrate as LB film form a rigid enough microporous structure which can be used with success for creation of sensitive chemical coatings on metallic electrodes of PQR with the mentioned above properties [4]. However, the techniques of LB films drawing demands use of the complex equipment and is labour-consuming. LB film consisting of one or several monolayers though possess exclusive speed and convertibility of the response, but because of very small thickness of a layer have no big sorbtion capacity and do not give sufficient sensitivity. Preparation of multilayered LB films with the purpose to increase of their sensitivity demands is a work of time. Besides, when that much increasing in quantity of monolayers, the degree of orderliness of LB films gradually decreases, and the condition of SAS molecules in them comes close to that is observed in usual bulk solid or liquid phases of corresponding SAS at the given temperature.
As is known, salts of metals with ionogenic SAS have much higher temperatures of fusion than an initial SAS. Thus they are well dissolved in organic solvents, and can be deposited on PQR electrodes by a way of simple application or by pulverization of solutions of corresponding SAS and subsequent drying the obtained coating. As was shown from our researches with the help of a method of the X-ray phase analysis (XRPA), the obtained by these means solid films possess the ordered periodic structure irrespective of their thickness. Recently we have developed methods of synthesis of some salts and complex compounds of d-transition metals with stearate anion ( $\left.\mathrm{St}^{-}\right)$and octadecylamine (ODA) of general formula $\mathrm{M}(\mathrm{ODA})_{\mathrm{N}} \mathrm{St}_{2}$, where $\mathrm{M}^{2+}$ are the ions of d-transition metals $\mathrm{Cu}(\mathrm{II}), \mathrm{Co}(\mathrm{II}), \mathrm{Ni}(\mathrm{II})$ and others, and $\mathrm{N}$ can vary from 0 up to 6 [6]. These compounds were investigated as chemical coatings for PQR sensors sensitive to vapours of hydrocarbons and other volatile organic substances.

In this work, studied was the sensitivity of PQR sensors with the chemical coatings of the specified type relative to the saturated vapours of some of the lowest alcohols. Due to the hydrophobic nature of these coatings, in our opinion, less others are subject to interfering influence of water vapours and can serve as the good sensitive coatings reacting to vapours of volatile organic substances on the basis of water vapours.

\section{Experimental}

In present work the following alcohols were investigated as analytes: methanol, ethanol, propanol, iso-propanol, butanol-1, butanol-2, iso-butanol and iso-pentanol. All the analytes had qualification "chemical pure" or "pure for a chromatography" and were used without additional refining.

For manufacturing the sensors the piezoquartz resonators manufactured by enterprise "UKRPIEZO" (Cherkassy, Ukraine) were used. They were made of AT-cut quartz plates and had nickel-silver electrodes and initial frequency of $10 \mathrm{MHz}$.

The following compounds were used as covering materials for PQR sensors: $\mathrm{CuSt}_{2}(1), \mathrm{Cu}(\mathrm{ODA})_{2} \mathrm{St}_{2}(2)$, $\mathrm{Cu}(\mathrm{ODA})_{4} \mathrm{St}_{2}$ (3), $\mathrm{Cu}(\mathrm{ODA})_{6} \mathrm{St}_{2}$ (4), Ni(ODA) ${ }_{6} \mathrm{St}_{2}$ (5), $\mathrm{Co}(\mathrm{ODA})_{6} \mathrm{St}_{2}(6)$.

Conditions of synthesis of the compounds and their deposition on PQR electrodes were described earlier [7]. The mass of the coating corresponding to the change of frequency of every PQR was $\left(-\Delta f_{\text {coat }}\right)=(7.0 \pm 0.5) \mathrm{\kappa Hz}$.

In the work, there used was the experimental setup described earlier [6]. It was consisted of a power unit of a direct current, the generator, a frequency meter, a personal computer, and also the tight glass chamber with thermostating water jacket and a neck with polished glass joint where the glass plug fitting was inserted. On the internal end of the plug the contacts for PQR were tightly inserted, and on its external part the portable generator was fixed. 
Table 1. Physical and chemical characteristics of the studied alcohols.

\begin{tabular}{|l|c|c|c|c|c|}
\hline \multicolumn{1}{|c|}{ Alcohol } & $\begin{array}{c}\text { Mol. mass, } \\
\text { Dalton }\end{array}$ & $\begin{array}{c}t_{\text {boil }} \\
(760 \mathrm{~mm} \mathrm{Hg}),{ }^{\circ} \mathrm{C}\end{array}$ & $\begin{array}{c}P_{\text {sat }}\left(25^{\circ} \mathrm{C}\right), \\
\mathrm{hPa}\end{array}$ & $C_{\text {sat }}\left(25^{\circ} \mathrm{C}\right), \mathrm{mg} / \mathrm{l}$ & $\Delta H_{\text {evap, }}, \mathrm{kJ} / \mathrm{mol}$ \\
\hline methanol & 32.04 & 64.7 & 168.3178 & 217.60 & 38.49 \\
\hline ethanol & 46.07 & 78.4 & 78.4233 & 145.78 & 43.27 \\
\hline propanol & 60.10 & 97.3 & 27.1416 & 65.82 & 45.31 \\
\hline iso-propanol & 60.10 & 82.2 & 59.9426 & 145.36 & 44.23 \\
\hline butanol-1 & 74.12 & 117.8 & 8.1557 & 24.39 & 46.39 \\
\hline butanol-2 & 74.12 & 99.6 & 24.1558 & 72.24 & 50.23 \\
\hline iso-butanol & 74.12 & 107.9 & 13.7751 & 41.20 & 45.67 \\
\hline iso-pentanol & 88.15 & 131.3 & 4.04598 & 14.39 & 58.19 \\
\hline
\end{tabular}

The sensor response was measured as a frequency change of PQR with the corresponding coating, when it was introduced in the chamber with an atmosphere of air saturated with vapours of corresponding alcohol at $(25 \pm 0.5){ }^{\circ} \mathrm{C}$, liquid phase of which was present at the bottom of the chamber. The PQR frequency was preliminary measured in an atmosphere of pure air at the same temperature and relative humidity. The value of the response, i.e., decreasing the $\mathrm{PQR}$ frequency in an atmosphere saturated with an analyte vapour $\left(-\Delta f_{\text {an }}\right)$ in comparison with its frequency in an atmosphere of pure air, was measured after an establishment of equilibrium (a constancy of frequency) that was reached no more than in 3-4 minutes after mounting PQR into the chamber. After extraction of the PQR from the chamber, its frequency in the atmosphere of pure air completely came back to the initial value approximately for the same period of time. For every analyte, it was executed 3 measurements of responses on $\mathrm{PQR}$ sensor with the same coating. Results of these measurements differed among themselves no more than by $10 \%$ were averaged and further used for construction of vector diagrams characteristic for every analyte.

\section{Results and discussion}

In Table 1, some physical and chemical characteristics of the investigated alcohols are presented: molecular weight, temperature of boiling at normal atmospheric pressure, partial pressure and concentration of saturated vapour of corresponding alcohol at $25^{\circ} \mathrm{C}$, and also molar enthalpy of evaporation.

Table 2 gives the values of responses $\left(-\Delta f_{\mathrm{an}}, \mathrm{Hz}\right)$ obtained for PQR sensors with the mentioned above coatings in the atmosphere of saturated vapours of the corresponding alcohols at $(25 \pm 0.5){ }^{\circ} \mathrm{C}$.

In the figure, the vector diagrams of the response group of the 6 PQR sensors for saturated vapours for each of the investigated alcohols are represented. These diagrams are the figures drawn connecting the direct lines of the ends of these six vectors, coordinates start with the general beginning and are directed at identical corners from each other. Number of a vector corresponds to the mentioned above number of the coating, and the length of a vector corresponds to a value of the corresponding $\mathrm{PQR}$ sensor response $\left(-\Delta f_{\text {an }}\right.$ in $\mathrm{Hz}$ ), obtained in saturated vapours of the given analyte. Each of these figures has the characteristic type and corresponds to a sensor (frequency) image for given analyte on given set of PQR sensors.

It is clearly seen in the figure, that the sensor images (i.e., the picture of relative lengths of response vectors) for each of all alcohols investigated by us has the unique character that can be used, at least, for identification of individual alcohols by using the set of

Table 2. The values of responses of $P Q R$ sensors obtained in atmosphere of saturated vapours of the corresponding alcohols at $(25 \pm 0.5){ }^{\circ} \mathrm{C}$. Covering materials for the PQR sensors: $\left.1-\mathrm{CuSt}_{2}, 2-\mathrm{Cu}(\mathrm{ODA})_{2} \mathrm{St}_{2}, 3-\mathrm{Cu}_{(\mathrm{ODA}}\right)_{4} \mathrm{St}_{2}, 4-$ $\mathrm{Cu}(\mathrm{ODA})_{6} \mathrm{St}_{2}, 5-\mathrm{Ni}(\mathrm{ODA})_{6} \mathrm{St}_{2}, 6-\mathrm{Co}(\mathrm{ODA})_{6} \mathrm{St}_{2}$.

\begin{tabular}{|l|c|c|c|c|c|c|}
\hline \multirow{2}{*}{ Alcohol } & \multicolumn{7}{|c|}{ Number of coating / Value of the response $\left(-\Delta f_{\text {an }}, \mathrm{Hz}\right)$} \\
\cline { 2 - 7 } & 1 & 2 & 3 & 4 & 5 & 6 \\
\hline methanol & 495 & 409 & 976 & 713 & 659 & 629 \\
\hline ethanol & 1467 & 523 & 2099 & 953 & 1066 & 1855 \\
\hline propanol & 1884 & 969 & 2781 & 1285 & 1864 & 2797 \\
\hline iso-propanol & 1807 & 868 & 1965 & 1371 & 1459 & 2737 \\
\hline butanol-1 & 2686 & 1221 & 2733 & 1568 & 2456 & 2789 \\
\hline butanol-2 & 1780 & 1087 & 1904 & 1376 & 2169 & 1933 \\
\hline iso-butanol & 2319 & 1170 & 2807 & 1413 & 2119 & 2757 \\
\hline iso-pentanol & 2744 & 1607 & 2851 & 2000 & 2873 & 3775 \\
\hline
\end{tabular}




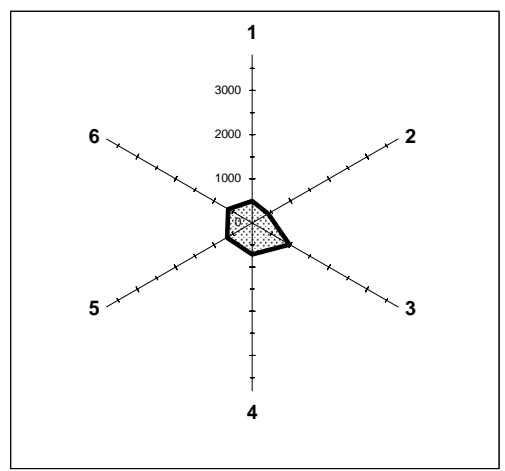

a. Methanol

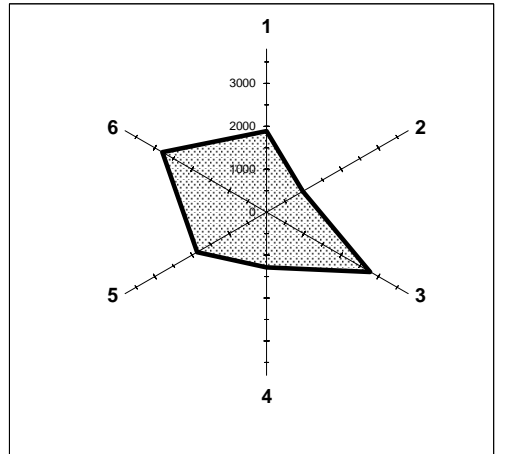

c. Propanol

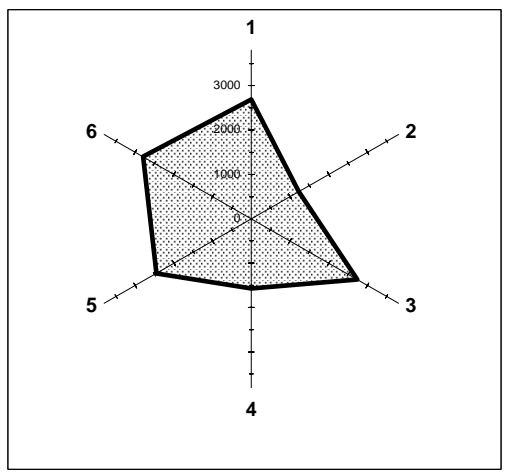

e. Butanol-1

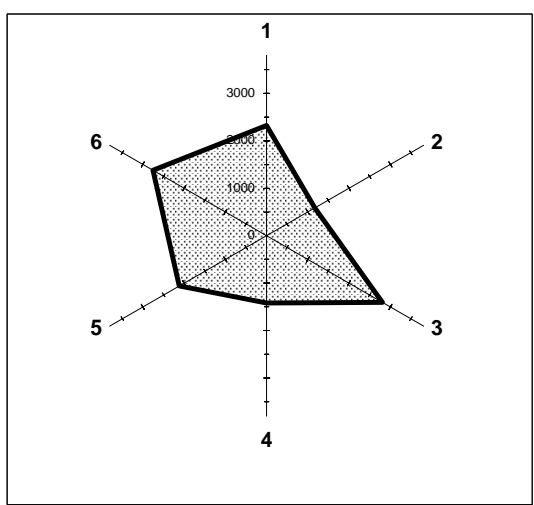

g. Iso-butano

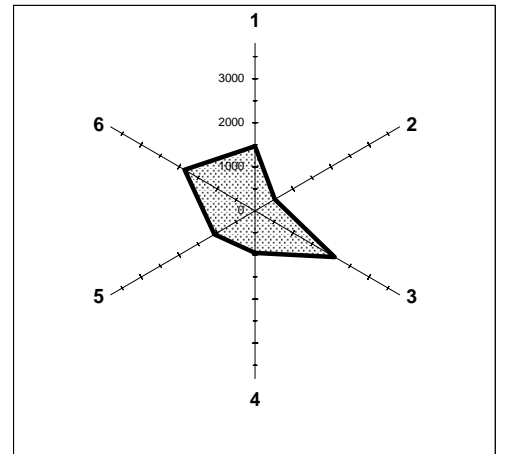

b. Ethanol

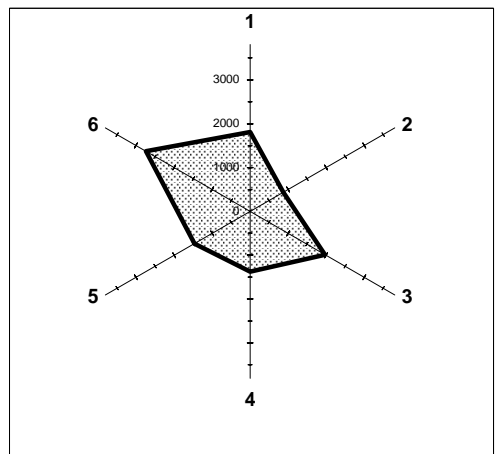

d. Iso-propanol

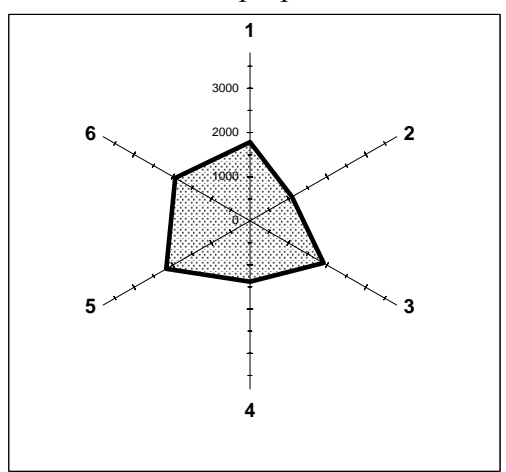

f. Butanol-2

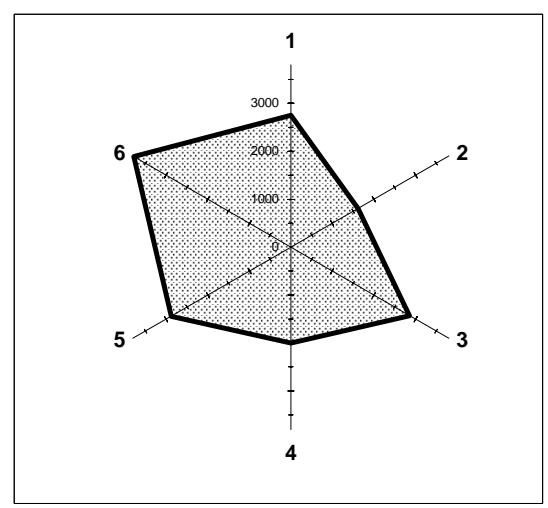

h. Iso-pentanol

Fig. 1. Sensor images of the saturated vapours of the lowest alcohols at $T=(25 \pm 0.5){ }^{\circ} \mathrm{C}$. Covering materials for PQR sensors: $1-\mathrm{CuSt}_{2}, 2-\mathrm{Cu}(\mathrm{ODA})_{2} \mathrm{St}_{2}, 3-\mathrm{Cu}(\mathrm{ODA})_{4} \mathrm{St}_{2}, 4-\mathrm{Cu}(\mathrm{ODA})_{6} \mathrm{St}_{2}, 5-\mathrm{Ni}(\mathrm{ODA})_{6} \mathrm{St}_{2}, 6-\mathrm{Co}(\mathrm{ODA})_{6} \mathrm{St}_{2}$. 
coatings of PQR sensors applied in this work. It is interesting to note that besides the distinctions between alcohols on relative values of responses on different PQR, between various alcohols, in general, it is also observed the distinction on average absolute size of responses of all the PQR sensors. If to compare data of Table 1 to those of Table 2, in some cases it is possible even to notice the tendency of increase in average absolute size of responses of all the PQR sensors on transition from alcohol with higher partial pressure of saturated vapour (for example, methanol) to that with the smaller value $P_{\text {sat }}$ (iso-amyl alcohol) at the same temperature. That is, at the same temperature all the investigated coatings give, on the average, the greater response in a case of saturated vapours of less volatile iso-amyl alcohol $\left(t_{\text {boil }}=131.3^{\circ} \mathrm{C}\right)$ than in the case of more volatile methanol $\left(t_{\text {boil }}=64.7^{\circ} \mathrm{C}\right)$. To be truth, by comparison of sensor images of iso-propanol $\left(t_{\text {boil }}=\right.$ $\left.82.2^{\circ} \mathrm{C}\right)$ and butanol-2 $\left(t_{\text {boil }}=99.6^{\circ} \mathrm{C}\right)$ such tendency is not observed. It is obvious that, in absence of sharp selectivity at the same concentration of analytes in a gas phase, the sorption of more volatile analyte by a sensor coating, in general, should be less than that of less volatile analyte. On the other hand, the concentration of saturated vapours at the same temperature for the former analyte is always higher than for the latter. Thus, when comparing the results of sorption for saturated vapours of different analytes at the same temperature, it is necessary to take into account two abovementioned factors that possess opposite action, but generally do not compensate each other. The parity of these factors can change with temperature what it is necessary to be taken into account when drawing up the database suitable for use of the multisensor assembly both in identification of vapours of individual analytes and the analysis of their mixtures (i.e., complex smells).

\section{Acknowledgements}

The work is partially supported by the scientific program of the National Academy of Sciences of Ukraine "Sensor systems and technologies" (grant 2C).

\section{References}

1. Q. Lucas, Y. Guerin, V. Benincasa // PITTCON'97 Atlanta, 1997, p. 613.

2. Lo Su-Chin // PITTCON'97 Atlanta, 1997, p. 70.

3. J.I. Korenman, T.A. Kuchmenko, Approaches to the analysis of foodstuff. Development of weightsensitive sensors // Rus. Khim. Zhurnal (Zhurnal Rossiyskogo Khimicheskogo Obschestva im. D.I. Mendeleeva), XLVI, No 4, p. 34-42 (2002) (in Russian).

4. L.I. Budarin, A.P. Filippov, B.A. Snopok, L.M. Pogorelaya, T.V. Snopok, Langmuir-Blodgett films as sensitive coatings for acoustic devices: Reversible absorption of ammonia on stearic acid and copper (II) stearate multilayers // Abstracts of the Seventh Intern. Conf. on Organized Molecular Films. Numana (Ancona), Italy. September, 10-15, 1995, p. 47.

5. F.M. Bobonich, A.S. Kovalenko, J.G. Voloshina, V.N. Solomaha, A.S. Korchev, A.P. Filippov, V.G. Ilyin, Features of molecular adsorption by template containing materials such as MCM-41 // Teoretich. i eksperiment. khimiya 35, No 6, p. 367-372 (1999) (in Russian).

6. A.P. Filippov, P.E. Strizhak, V.G. Ilyin, Quartz crystal microbalance modified with $\mathrm{Cu}(\mathrm{II})$ stearate and octadecylamine complexes for organic vapor detection // Sensors and Actuators (2006) in press.

7. A.P. Filippov, P.E. Strizhak, T.G. Serebry, A.I. Tripolsky, B.A. Snopok, V.A. Havrus, T.S. Ivaschenko, New materials of coatings for discrimination of hydrocarbons by multisensor system combined with gas chromatograph // Teoretich. i eksperiment. khimiya 40, No 6, p. 371376 (2005) (in Russian). 